\title{
O Prazer em estar na Escola: A Gala de Cinema na Aula
}

\author{
Pleasure to be at School: The Cinema Festival in the Classroom
}

\author{
Teresa Martins*, Teresa Pessoa** \\ *Agrupamento de Escolas de Soure, **Universidade de Coimbra, Portugal
}

\begin{abstract}
Resumo
Numa era tecnológica de crise global, pouco favorável ao valor de educar, é urgente despertar o prazer em estar na escola. Esta investigação-ação, desenvolvida numa escola portuguesa da zona centro em 2012/ 2013 e 2013/ 2014, consiste num trabalho de reflexão sobre a prática relativamente à utilização pedagógica do vídeo pelos alunos, como fonte de despertar o prazer em estar na escola. Em cada ano os alunos organizaram uma Gala de Cinema para disseminar os produtos finais junto da comunidade educativa. A análise SWOT dos depoimentos dos alunos permitiu identificar as vantagens e desvantagens (cognitivas, afetivas, tempo, esforço).

Palavras-chave: aprendizagem do inglês, vídeo, prazer, autonomia
\end{abstract}

\begin{abstract}
At a technological age of global crisis, which is not very favourable to the value of education, it is urgent to awake the pleasure to be at school. The current action-research study developed in a Portuguese school from the centre of Portugal, in 2012/ 2013 and 2013/ 2014, is a reflection on the pedagogical use of video by students, as a source of awakening the pleasure to be at school. Every year the students organized a Cinema Festival to disseminate their final products among the school community. The SWOT analysis of the students' reports identified the advantages and disadvantages (cognitive, affective, time, effort). Keywords: learning English, video, pleasure, autonomy
\end{abstract}

\section{Introdução}

As escolas portuguesas têm vindo a sofrer de uma “compressão do tempo e do espaço” (Hargreaves, 1998), numa era tecnológica de crise global pouco favorável ao valor de educar, na qual a escola inclusiva, o ensino formal de qualidade e os agentes educativos são muitas vezes desvalorizados. “A escola pública portuguesa tem sido submetida nos últimos anos a uma multiplicidade de medidas e programas reformadores com implicações visíveis aos níveis da sua organização e administração, das relações laborais e das identidades profissionais dos professores, do clima de trabalho e das metodologias pedagógicas, da reconfiguração das relações de poder e dos perfis de liderança, entre outras dimensões pertinentes” (Torres, 2008, p.77). Barroso (2005) considera que a escola, ultrapassando a sua função original de educação e instrução, passa a ser chamada a responder aos apelos da sociedade civil com a massificação do ensino e a manutenção do modelo escolar de "ensinar a muitos como se fosse um só”. A escola pós-moderna globalizada continua a focar a sua atenção nos conteúdos, exames, rankings (como fazer) e dificilmente responde aos desafios da sociedade atual (para que ensinar), como refere Brandão (2003). Todos estes condicionalismos, que levam educadores e alunos a passarem cada vez mais tempo das suas vidas no recinto escolar, têm contribuído para a desmotivação generalizada, tornando-se assim premente despertar o prazer em estar na escola.

Raposo (2012) adverte que o principal desafio do professor da era pós-moderna consiste na redescoberta de metodologias de despertar o prazer em estar na escola e de aprender. Marcelino (1997) defende que a vertente lúdica é uma aliada da criatividade, pois o jogo fomenta a reflexão, problematização, diálogo e posicionamento crítico do aluno. A utilização de recursos audiovisuais em contexto educativo contribui para fomentar a motivação de alunos e professores para os conteúdos programáticos que estão a ser lecionados (Bassili, 2006). O Prazer em estar na Escola: A Gala de Cinema na Aula surge da combinação da vertente lúdica no processo de ensino-aprendizagem com a utilização pedagógica do vídeo num contexto de "nativos digitais", fascinados pela imagem, vídeo, som, utilização das tecnologias da informação, em detrimento de leituras e de uma metodologia mais expositiva.

“Os nossos alunos mudaram radicalmente. Já não são os mesmos para os quais o nosso sistema de ensino foi concebido para ensinar” (Marc Prensky, 2001, p.1). Na verdade, a geração nascida a partir da década de 90 do século XX, "Nativos Digitais”, cresceu numa era de rápida difusão da tecnologia digital - computadores, videojogos, câmaras de vídeo, telemóveis, Internet processando a informação de forma diferente das gerações anteriores, designadas por "Imigrantes Digitais”, nomeadamente os seus professores. O desafio da escola de hoje consiste na tomada de consciência de que os intervenientes e o contexto educativo mudaram, o que requer uma nova forma de pensar. Os alunos, "Nativos Digitais", sentem dificuldade de concentração e de motivação numa sala de aula que utilize predominantemente a linguagem da era pré-digital. Prensky (2012) defende que os jovens precisam de competências e ferramentas que lhes permitam ser bons alunos mas também melhores pessoas, devidamente equipadas para enfrentar os desafios da vida real e do mundo em rápida evolução, o qual se distancia do passado. Isto requer que a escola do século XXI integre meta-competências como a promoção do pensamento crítico, a resolução de problemas, vídeo e programação, tal como até aqui tem incluído a leitura e a escrita. A sala de aula já não é um espaço em que o professor expõe a matéria e os alunos escutam e tiram apontamentos. Em 
parceria, os alunos encontram informação, usam a tecnologia e outros recursos, e criam produtos que demonstrem a sua compreensão das matérias em estudo. Os professores fazem as perguntas certas, asseguram a qualidade e rigor e acrescentam contexto adequado (Prensky, 2012). A educação deveria fomentar a criatividade dos alunos, em todas as disciplinas e áreas de interesse, com as ferramentas ao seu alcance, de forma a permitir o desenvolvimento de produtos finais com criatividade e competência e a respetiva divulgação. $\mathrm{O}$ vídeo será uma dessas ferramentas.

Nos últimos anos, as escolas têm sido equipadas com tecnologias que nem sempre estão a ser rentabilizadas da melhor forma. O vídeo não é exceção. Em primeiro lugar, este facto deve-se à falta de formação dos docentes para o utilizar na sala de aula. Por vezes, a formação limita-se à componente tecnológica, negligenciando as potencialidades pedagógicas do vídeo. Há que aprender a rentabilizá-lo de forma eficaz, utilizando-o como um meio propício a uma aprendizagem mais dinâmica, contextualizada e centrada no aluno/ formando, tendo em vista o sucesso nas aprendizagens (Caldas \& Silva, 2001; Ferrés, 1995; Ferrés, 1998). Qualquer jovem pode produzir pequenos vídeos no seu portátil, telemóvel ou iPad e partilhá-los no YouTube, Facebook, Google Vídeos ou Yahoo Vídeos (Prensky, 2001; Silva, 2010). Em contexto escolar formal, os alunos já começam a tratar os temas abordados em fotovídeos, documentários ou curta-metragens de sua autoria (Volpato, 2012), mas quase sempre a edição é muito dirigida pelo professor. Tanto na didatização como na produção de filmes o papel do aluno na aprendizagem tem sido diminuto. A investigação que analisa o processo de ensino/ aprendizagem com recurso ao vídeo, apresentando diversas abordagens eficazes, tem emergido, mas também sugere a necessidade de se continuar a explorar esta área de estudo.

Tendo como ponto de partida o enquadramento teórico relativamente às dinâmicas atuais da escola que têm contribuído para a motivação e desmotivação de alunos e professores e o papel do vídeo em educação, passaremos, de seguida, a contextualizar e a descrever o estudo.

\section{Metodologia}

O presente estudo empírico insere-se no paradigma de investigação qualitativa, de caráter exploratório e interpretativo, privilegiando a utilização do vídeo como processo (Ferrés, 1997). Relativamente aos objetivos, a presente investigação visa, de um modo geral, compreender de forma crítica a utilização pedagógica do vídeo. Os objetivos específicos consistem em descrever percursos pedagógicos mediados pelo vídeo; caracterizar o contributo do vídeo para despertar o prazer em estar na escola; identificar as dimensões do quotidiano e vivências dos alunos na construção de filmes e reconhecer as implicações das aprendizagens mediadas pelo vídeo na motivação dos alunos e na promoção da reflexão crítica.

Em 2012/ 2013 e 2013/ 2014 procurámos "ver com olhos de ver” a produção de vídeos pelos próprios alunos, em língua inglesa com legendagem em português, que vínhamos promovendo desde 2005/ 2006, numa parceria transdisciplinar desenvolvida no âmbito do Programa Sócrates, Comenius 1, intitulada "Encontros Europeus Partilha de Experiências”, cujos produtos finais eram videogramas desenvolvidos pelas respetivas escolas parceiras. Esta base de trabalho constituiu a génese da presente investigação alicerçada no Estudo A - Gala de Cinema de $10^{\circ}$ ano - e Estudo B - Gala de Cinema de $11^{\circ}$ ano - de 2012/ 2013 a 2013/ 2014. Em cada ano, os alunos organizaram uma Gala de Cinema para mostrar os seus filmes à comunidade educativa. De 2005 a 2012 foram concluídos 31 filmes de $10^{\circ}$ ano (196 alunos). Em 2012/ 2013 foram produzidos 6 filmes (30 alunos) e em 2013/ 2014 foram produzidos 6 filmes (36 alunos), conforme a tabela 1 .

Tabela 1.

Filmes de $10^{\circ}$ Ano

\begin{tabular}{lcc}
\hline Ano Letivo & $\mathrm{N}^{\circ}$ de Filmes & $\mathrm{N}^{\circ}$ de Alunos \\
\hline $2005 / 06$ & 1 & 6 \\
$2006 / 07$ & 4 & 17 \\
$2007 / 08$ & 4 & 25 \\
$2008 / 09$ & 5 & 46 \\
$2009 / 10$ & 6 & 70 \\
$2010 / 11$ & 6 & 15 \\
$2011 / 12$ & 5 & 17 \\
$2012 / 13$ & 6 & 30 \\
$2013 / 14$ & 6 & 36 \\
TOTAL & 43 & 262 \\
\hline
\end{tabular}

De 2005 a 2012 foram produzidos 57 filmes de $11^{\circ}$ ano (259 alunos). Em 2012/ 2013 foram realizados 6 filmes (18 alunos) e 5 spots publicitários (12 alunos). Em 2013/ 2014 foram concluídos 2 filmes e 5 spots publicitários (12 alunos). Em 2014/ 2015 foram realizados 9 spots publicitários (21 alunos), como se vê na tabela 2.

Tabela 2.

Filmes de $11^{\circ}$ Ano

\begin{tabular}{ccc}
\hline Ano Letivo & N $^{\circ}$ de Filmes & $\mathrm{N}^{0}$ de Alunos \\
\hline $2005 / 06$ & 4 & 15 \\
$2006 / 07$ & 6 & 32 \\
$2007 / 08$ & 8 & 39 \\
$2008 / 09$ & 9 & 60 \\
$2009 / 10$ & 9 & 53 \\
$2010 / 11$ & 15 & 41 \\
$2011 / 12$ & 6 & 19 \\
$2012 / 13$ & 11 & 30 \\
$2013 / 14$ & 7 & 12 \\
$2014 / 15$ & 9 & 21 \\
TOTAL & 84 & 322 \\
\hline
\end{tabular}

No Estudo A estiveram envolvidos 66 alunos (33 raparigas e 33 rapazes) como se comprova na tabela 3.

Tabela 3.

Sujeitos do Estudo A - Gala de Cinema $10^{\circ}$ Ano

\begin{tabular}{cccc}
\hline Ano Letivo & Raparigas & Rapazes & TOTAL \\
\hline $2012 / 2013$ & 13 & 17 & 30 \\
$2013 / 2014$ & 20 & 16 & 36 \\
\hline
\end{tabular}


No Estudo B estiveram envolvidos 48 alunos (26 raparigas e 22 rapazes) como se comprova na tabela 4 .

Tabela 4.

Sujeitos do Estudo B - Gala de Cinema $11^{\circ}$ Ano

\begin{tabular}{lccc}
\hline Ano Letivo & Raparigas & Rapazes & TOTAL \\
\hline $2012 / 13$ & 20 & 16 & 36 \\
$2013 / 14$ & 6 & 6 & 12 \\
\hline
\end{tabular}

Os instrumentos de recolha de dados consistiram em notas de campo relativamente à observação de comportamentos e atitudes dos alunos bem como à evolução do processo em curso; guiões dos filmes redigidos em português com tradução das falas em inglês; fichas técnicas dos filmes com indicação do material utilizado, local das filmagens, distribuição das tarefas e sinopse; os próprios filmes realizados pelos alunos; recolha de depoimentos dos alunos que participaram no estudo de 2012 a 2014 para avaliação do grau de satisfação.

No tratamento dos dados procedeu-se à análise de conteúdo fílmico pelo processo de categorização. Foi construída uma matriz de análise que contempla: ano letivo; ano de escolaridade/ turma; nome/ género de filme; temas abordados; número de alunos participantes. A análise SWOT dos depoimentos dos alunos permitiu identificar as vantagens (cognitivas/ afetivas) e desvantagens (afetivas, tempo, esforço).

\section{Resultados}

Da análise do conteúdo fílmico das Galas de Cinema de $10^{\circ}$ e $11^{\circ}$ de 2012 a 2014 resultaram 6 matrizes com a designação de Listagens de Filmes $10^{\circ}$ Ano 2012/ 2013 e 2013/ 2014; Listagens de Filmes $11^{\circ}$ Ano 2012/ 2013 e 2013/ 2014 e 3 Listagens de spots publicitários de 2012 a 2015, respetivamente. Constata-se que há preocupações comuns nos filmes de $10^{\circ}$ ano subordinados ao tema aglutinador "Ser Jovem: Pensar os Valores": comportamentos de risco (álcool, toxicodependência, gravidez na adolescência), distúrbios alimentares, violência doméstica, bullying. No $11^{\circ}$ ano, os alunos refletem sobre temas ambientais "O Homem é poderoso mas a Natureza o é mais. Concordas?” Os jovens de $11^{\circ}$ ano partilham a sua preocupação com as mudanças climatéricas, fogos florestais, poluição. No $11^{\circ}$ ano, os jovens também produzem spots publicitários comerciais e institucionais. Após a produção de filmes, os alunos procederam à respetiva auto e heteroavaliação, tendo escolhido o melhor filme de cada ano na Gala de Cinema, ou por sua opção, na ausência de uma apresentação pública dos filmes à comunidade, a votação foi efetuada na sala de aula.

Da análise SWOT, os alunos salientam, como vantagens de natureza cognitiva, que a produção de filmes contribui para promover a aprendizagem a nível da utilização das tecnologias audiovisuais mediadas pelo vídeo; dos conteúdos programáticos, bem como da língua inglesa tanto na sua competência linguística como oral. São destacadas as seguintes vantagens de natureza afetiva: motivação, criatividade e autonomia; melhoria das relações interpessoais; satisfação com o processo de ensino-aprendizagem; utilidade para o futuro; vontade de repetir a experiência. Apesar de existir um número superior de unidades de registo abrangendo as vantagens, são apontados os seguintes constrangimentos: duração da tarefa; falta de disponibilidade; esforço.

\section{Discussão}

As experiências efetuadas com a produção de vídeos, acima descritas, constituíram uma mais-valia tanto para os alunos como para os professores envolvidos, tendo sido atingido os objetivos delineados. A produção de vídeos é benéfica para o aprendente de língua estrangeira que tem a oportunidade de visualizar e corrigir o seu desempenho (Gromik, 2008; Levy \& Kennedy, 2004). A produção de filmes em inglês fomentou a autonomia dos alunos que, em trabalho de grupo, pesquisaram um tema e o desenvolveram em suporte de vídeo (Wenden, 2002). Discutir temas de interesse dos próprios alunos por meio de histórias fictícias é motivador, pois torna mais fácil os jovens refletirem sobre situações hipotéticas para depois pensarem em situações reais, gerando assim um envolvimento maior (Volpato, 2012). Importa, contudo, realçar o processo em si e não apenas a qualidade dos conteúdos produzidos, pois o "vídeo-processo" contribui para uma aprendizagem dinâmica, na qual os alunos desempenham um papel ativo e criativo na pesquisa de informação, gravação e edição de produtos audiovisuais (Ferrés, 1997). O vídeo didático transforma a escola num centro não apenas focado na simples transmissão de saberes, mas também com o conhecimento completo por contemplar vários tipos de experiências: conhecimentos, sensações, emoções, atitudes, intuições (Ferrés, 1995; Prensky, 2012).

No entanto, não podemos omitir os contratempos que surgem em projetos desta natureza. Fonseca (1995) afirma que a força comunicativa dos audiovisuais supera os obstáculos que possam surgir ao longo da caminhada: dificuldades de edição ou falta de tempo; o professor dinamizador pode não dominar as técnicas audiovisuais; nem todas as escolas dispõem de recursos suficientes para o desenvolvimento desta atividade, o que compromete a qualidade do trabalho produzido, nomeadamente a nível do som e da imagem; com o aumento de alunos por turma e do tempo de permanência na escola, a correção de guiões e a orientação dos alunos ao longo de todo o processo de realização e edição do vídeo exige uma sobrecarga ao trabalho inerente à docência.

Deixamos algumas questões que poderiam servir de objeto de estudo para futuras intervenções desta natureza:

- De que forma o vídeo está organizado e é utilizado na aula de língua estrangeira nas escolas portuguesas?

- Qual a importância do vídeo na escola portuguesa do século XXI?

- Dos Nativos Digitais à Sabedoria/ Cidadania Digital em Portugal: Será possível em tempo de crise? Como?

Para terminar este trabalho, não podemos deixar de salientar que o vídeo poderá constituir uma mais-valia 
em futuras práticas de Supervisão Pedagógica, tanto para professores como para alunos. A auto e a heteroavaliação ajudam a refletir sobre as práticas e aperfeiçoá-las. O acompanhamento que os professores dão à elaboração dos guiões, às filmagens e edição contribui para um trabalho colaborativo entre docentes e discentes, o que desperta o prazer em estar na escola. O vídeo promove o “olhar com olhos de ver para ajudar a crescer”, isto é, encarar os temas com outra perspetiva, de fora para dentro e aprender com eles.

\section{Referências}

Barroso, J. (2005). Politicas Educativas e Organização Escolar. Lisboa: Universidade Aberta.

Bassili, J. N. (2006). Promotion and Prevention Orientations in the Choice to Attend Lectures or Watch Them Online. Journal of Computer Assisted Learning, 22, (pp. 444-455).

Brandão, V. (2003). A Escola do Prazer: O lazer numa instituição voltada para obrigações. Anais do VII EnFEFE - Encontro Fulminense de Educação Física Escolar. Universidade Federal Fluminense. Niteroí R.J., 25-28.

Caldas, J. M. \& Silva, B. D. (2001). O vídeo na escola em Portugal. Atas do VI Congresso Galaico-Português de Psicopedagogia. Braga: Centro de Estudos em Educação e Psicologia da Universidade do Minho, I, 383-394.

Ferrés, J. (1995). Vídeo e Educação. Porto Alegre: Artes Médicas Sul Ltda.

Ferrés, J. (1997). Vídeo y educación. Barcelona: Editora Laia.

Ferrés, J. (1998). El vídeo en el aula. Comunicación y pedagogía: Nuevas tecnologías y recursos didácticos, 154, 46-49.

Fonseca, C. (1995). A Noética do Vídeo Etnográfico (pp.187-206). Horizontes Antropológicos, 2, ano 1. Porto Alegre: Porto Alegre.

Gromik, N. (2008). Windows Movie Maker in the English as a Foreign Language Class. Disponível em: http://www.innovateonline.info/pdf/vol1_issue1/ Video_Game_Studies_and_the

Emerging_Instructional_Revolution.pdf Consultado em 27/ 05/ 2013.

Hargreaves, A. (1998). Os professores em tempos de mudança: O trabalho e a cultura dos professores na idade pós-moderna. Alfragide: McGraw Hill.

Levy, M. \& Kennedy, C. (2004). A Task-Cycling Pedagogy Using Stimulated Reflection and Audio-Conferencing in Foreign Language Learning. Language Learning \& Technology, 8, 50-69.

Marcelino, N. (1997). Pedagogia da animação. Belo Horizonte: Papirus.

Prensky, M. (2001). Digital Natives, Digital Immigrants. On the Horizon. MCB University Press. Vol. 9, No. 5, (October 2001).

Prensky, M. (2012). From Digital Natives to Digital Wisdom: Hopeful Essays for 21st Century Education. Corwin.

Raposo, A. (2012). Professores e contextos de trabalho: Como se tece a ação docente numa escola em mudança.
Dissertação de Mestrado em Supervisão Pedagógica e Avaliação de Docentes da Faculdade de Ciências Sociais e Humanas da Universidade Católica Portuguesa. Lisboa: Universidade Católica.

Silva, A. F. M. D. (2010). O uso do vídeo no processo de ensino-aprendizagem: análise de vídeos em manuais escolares e percepções dos professores e alunos sobre as potencialidades pedagógicas do vídeo. Dissertação de Mestrado em Ciências da Educação. Área de Especialização em Tecnologia Educativa apresentada ao Instituto de Educação e Psicologia da Universidade do Minho. Braga: Universidade do Minho.

Torres, L. (2008). Modos de regulação cultural nas organizações escolares: um estudo sobre os perfis de liderança numa escola secundária. Revista de Educação, XVI: 77-96.

Volpato, M. (2012). Dinâmica de produção de filmes por alunos muda a realidade na escola. Consultado em: http://revistaescola.abril.com.br/gestao-escolar/videobullying-642479.shtml

Wenden, A. (2002). Learner Development in Language Learning. Applied Linguistics, Vol. 23, 32-55. 